\title{
Agent-based modeling of the dynamics of mammal-eating killer whales and their prey
}

\author{
J. Ward Testa ${ }^{1,2, *}$, Kenrick J. Mock ${ }^{3}$, Cameron Taylor ${ }^{3,4}{ }^{,}$Heather Koyuk ${ }^{3,5}$, \\ Jessica R. Coyle ${ }^{3,6}$, Russell Waggoner ${ }^{3,7}$ \\ ${ }^{1}$ National Marine Mammal Laboratory, Alaska Fisheries Science Center, National Marine Fisheries Service, \\ National Oceanic and Atmospheric Administration, Seattle, Washington 98115, USA \\ ${ }^{2}$ Biological Sciences Department, University of Alaska Anchorage, Anchorage, Alaska 99508, USA \\ ${ }^{3}$ Department of Mathematical Sciences, University of Alaska Anchorage, Anchorage, Alaska 99508, USA \\ ${ }^{4}$ Present address: 3604 E 19th Ave, Anchorage, Alaska 99517, USA \\ ${ }^{5}$ Present address: 12311 32nd Ave, NE \#2, Seattle, Washington 98125, USA \\ ${ }^{6}$ Present address: Department of Biology, University of North Carolina, Chapel Hill, North Carolina 27599, USA \\ ${ }^{7}$ Present address: $2701 \mathrm{~W}$ 32nd \#4, Anchorage, Alaska 99517, USA
}

\begin{abstract}
The role of mammal-eating, or transient, killer whales Orcinus orca in the decline of various marine mammal populations in Alaska is controversial and potentially important in their recovery. Classical predator-prey models are insufficient to describe the dynamics of a single predator on the number of prey types known for these predators, and there are few populationlevel data that could be used to parameterize such models. As an heuristic framework for this more complicated system, we developed an agent-based model of killer whales with plausible energetics and behavior. We calibrated and validated the model using single-prey scenarios (a community of generic 'Seals') against published expectations for prey consumption rates, killer whale group dynamics, and demography. We then explored the emergent properties of single-prey models and of 3-prey models using the 'Seals' as primary prey, a generic small population of 'Sea Lions', and seasonally available large 'Whales'. The single-prey model gave results that were intuitively reasonable and responsive to underlying parameters but were also sensitive to encounter/killing rates, as expected in classic predator-prey models with similar parameters. However, the dynamics included long time lags ( $30 \mathrm{yr})$ with strong shifts in predator age structure and vital rates. In multi-prey scenarios in which the importance of seasonally available large whale prey was manipulated, large whale prey had the potential to augment killer whale numbers somewhat but had a minimal effect on the overall dynamics, whereas perturbing the carrying capacity of the primary prey created strong numeric shifts in killer whale population size and consequent indirect effects on both alternate prey. No predictive utility is suggested due to the absence of such elements as spatial realism, explicit prey-switching and more realistic prey structure, but the models suggest that we consider more complicated numerical dynamics of killer whales in discussions of their impact on prey.
\end{abstract}

KEY WORDS: ABM - Individual-based models - IBM - Orcinus orca - Population dynamics · Predator-prey

Resale or republication not permitted without written consent of the publisher

\section{INTRODUCTION}

The role of mammal-eating, or transient, killer whales Orcinus orca in the decline of various marine mammal populations in Alaska is controversial and potentially important in their recovery. Springer et al. (2003) hypothesized that declines in harbor seal Phoca vitulina, Steller sea lion Eumetopias jubatus, northern fur seal Callorhinus ursinus, and sea otter Enhydra lutris populations in Alaska were driven by 
the over-harvest of great whales in the 1950s to 1970s, leading to a cascade of prey-switching by transient killer whales from these large prey species to smaller, less desirable ones. That hypothesis is disputed by some researchers, who cite inconsistencies in the timing of declines, insufficient observed killer whale predation on large whales and the absence of prey declines in areas with the same patterns of commercial whaling (DeMaster et al. 2006, Mizroch \& Rice 2006, Mehta et al. 2007, Trites et al. 2007, Wade et al. 2007). Whatever the role of commercial whaling and prey-switching by killer whales, it is known that killer whales prey on threatened marine mammal populations in the North Pacific (e.g. sea otters and Steller sea lions) and that the magnitude of that predation is at least a plausible factor either in the decline of those populations or their failure to recover (Estes et al. 1998, Heise et al. 2003, Springer et al. 2003).

Estimations of killer whale numbers and rates of predation on various marine mammal species now have high research priority, but how we interpret these new data is dependent on having an adequate theoretical framework. Thus far, only simplistic, static models of killer whale consumption have been constructed to test the plausibility of killer whale impact on other species (e.g. number of whales $x$ killing rate $=$ estimated impact) (e.g. Barrett-Lennard et al. 1995, Williams et al. 2004), and none have attempted to predict behavioral or demographic responses of the predator to a changing prey community. Classical approaches to modeling predatorprey relationships are rooted in the Lotka-Volterra equations. These entail estimation of a 'functional response' that defines the number of prey that can be captured and consumed as a function of the densities in which they are encountered and a 'numeric response' of the predator that describes the efficiency with which prey are converted into predators. Data that might support a form for either of these functions in transient killer whales and their prey are only beginning to emerge. Ford et al. (2007) cite a possible relationship of slowing growth of transient killer whale and population size of harbor seals, while studies of diet in transient killer whales are accumulating but have not been combined with information on prey-specific abundance or availability. Moreover, there is little theoretical development for dynamic predator-prey systems involving a single predator interacting with the number and diversity of prey species hunted by transient killer whales, or for understanding how hunting in groups might affect even simple models.
While data to support the development of a classical predator-prey model for killer whales are sparse, research on the biology and behavior of killer whales as individuals and groups has greatly accelerated in recent years (e.g. Heise et al. 2003, Ford et al. 2005, 2010, Mehta et al. 2007, Dahlheim \& White 2010, Barrett-Lennard et al. 2011). This suggests that one approach to the theoretical development of predatorprey models might be the implementation of individual-based (IBM) or agent-based models (ABMs) that use these recent studies to evaluate properties of predator-prey relationships that emerge from our knowledge, and uncertainties, about the biology of individuals and social groups of transient killer whales. At this point, we do not know the relationship between the killing rates of transient killer whales and prey densities (functional response) nor the relationship between prey abundance or consumption and population growth in killer whales (numeric response). However, we have some ideas about the energetic requirements of these large predators, the size and structure of hunting groups, and the number and kinds of prey pursued and killed in certain places and times of the year. Following the guidelines proposed by Grimm \& Railsback (2005) for IBM modeling in ecology, we propose that our knowledge at these levels can be used in an IBM to reproduce the characteristic emergent patterns in group size, prey consumption and demographics of killer whales and their prey. We can then explore how assumptions of such models influence more complex emergent properties, such as functional and numeric responses, or how depletion of selected prey resources (e.g. removal of large whales by humans) might change predator-prey dynamics under different assumptions. Perhaps more importantly, such an exercise may identify critical conceptual elements and real-world data essential to understanding fundamental characteristics of the killer whale predator-prey system in the NE Pacific Ocean.

Our broad objective is to use biological knowledge at the level of individuals and groups of mammaleating killer whales to model theoretical expectations that emerge in the population dynamics of these whales and their prey. Recent studies of prey consumption and the structure of hunting groups (Baird \& Dill 1995, 1996, Baird \& Whitehead 2000, Dahlheim \& White 2010) of transient killer whales are used to formulate and parameterize the components of an agent-based model and to make comparisons to certain emergent properties of these models as a form of model validation. Detailed information on the demography of transient killer whales was unavailable when the project was initiated, so we relied on com- 
parisons to the demography of resident killer whales (Olesiuk et al. 1990) and to characteristic patterns of density-dependent or consumption-dependent changes in other large mammal populations (Gaillard et al. 1998, Eberhardt 2002). More recent work (Ford et al. 2007) confirms that the population parameters of transients in British Columbia are very similar to those we used. Knowledge of killer whale energetics is sparse (Kriete 1995, Williams et al. 2004, Williams \& Noren 2009, Noren 2011), but we patterned our approach after those of Moen et al. (1997) and Winship et al. (2002) with adjustments for the allometric relationship suggested by Williams et al. (2004).

More specifically, our objectives were to (1) implement an ABM with plausible energetics at the individual level and behavior of individuals and groups derived from published sources, (2) calibrate and validate the model using single-prey scenarios against published expectations for prey consumption rates, killer whale group dynamics, and demography, and (3) quantify and evaluate emergent properties of single and multiple prey scenarios with regard to killer whale demography and the functional and numeric responses of killer whales to prey abundances. We then simulated scenarios involving changing numbers of a primary prey population of generic 'Seals' together with 2 alternative prey: 'Sea Lions' and seasonally migrating large 'Whales'.

\section{MATERIALS AND METHODS}

The purpose of the model is to simulate the population dynamics and predator-prey interactions of transient killer whales as emergent properties of their basic individual biology and behavior, much of which is better known than their population dynamics. The model components include submodels for the energetics, growth, demography, and group dynamics of transient killer whales, prey demography, and predator-prey interactions. Grimm et al. (2006) recommended a standard protocol for describing IBM in 3 stages (overview, design concepts, and details), which we will follow. A model overview is provided below. Design concepts and model details are available in the supplement at www.int-res.com/articles/ suppl/m466p275_supp.pdf.

\section{State variables and scales}

Model killer whales possessed the following state variables: a unique identification (ID); birthdate (and therefore age); sex; body mass (and therefore condition relative to a target growth curve); reproductive status (pregnant or lactating), identity of mother (and therefore relationships to siblings and other relatives); membership in a hunting group; and social memory (record of past associations with other whales that determine group composition, cohesion, joins, and splits).

The only environmental state variable of importance to killer whales in the model was prey abundance. No spatial component was modeled, i.e. prey were assumed to be randomly distributed and probabilistically encountered by each group of hunting whales. Individual killer whales were aggregated into hunting groups according to rules of association that were based on relatedness, past associations, and expected hunting success for a given prey base. The state variables of each hunting group were group size (number of individual whales) and the 'effective group size' that represented the hunting effectiveness of the group in adult equivalents (i.e. juveniles were discounted in relation to adults due to their presumed inexperience in hunting). Effective group size determined the hunting effectiveness of the group against each prey type, while the group size and other state variables of the individual killer whales determined how prey were partitioned to meet energetic requirements of the killer whales. We made the simplifying assumption of a constant energy content for the mass of both predators and prey to shorten computation time and used other adjustments in metabolic rates and thresholds to compensate for potential biases that might result from this (see model details in the supplement).

\section{Process overview and scheduling}

The model was executed in daily time steps (Fig. 1). Prey were represented in the model by userdefined species composed of 2 age classes: youngof-the-year and all older animals. The densitydependent dynamics of each class in the absence of predation were non-linear, with maximum productivity at roughly $75 \%$ of equilibrium and demographic responses to density occurring first in juvenile survival, then adult reproduction and survival (Eberhardt 2002) (see model details in the supplement). Our approach assumed underlying probabilities of birth and survival that occur when whales are unconstrained by prey availability and modified these rates downward based on the ability of each whale to maintain its body mass above certain 


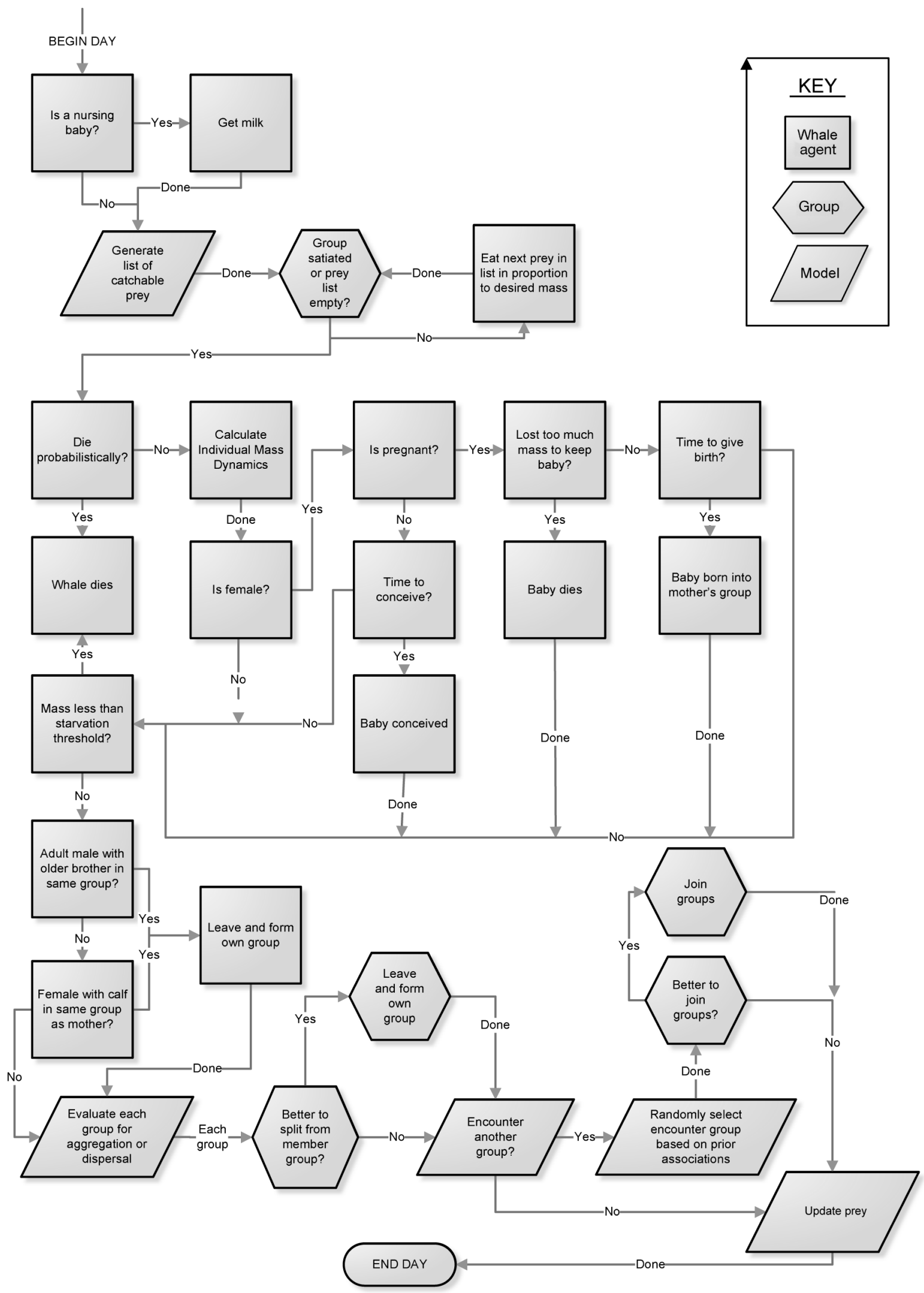

Fig. 1. Model execution of daily routines illustrated with a flow diagram. Object shapes denote actions taken at a group, individual, or model level 
thresholds relative to an expected body mass that was specified by age and gender-specific growth curves. Baseline probabilities of becoming pregnant or dying were chosen based on those reported by Olesiuk et al. (1990) for resident killer whales and yielded maximum rates of annual population growth with unlimited food around $\lambda=1.04$, as suggested by those authors. Each group was allowed to 'encounter' the available prey, the outcome of those encounters were determined probabilistically, and consumption was translated into energy needed for respiration, growth, and reproduction (Fig. 2). Shortfalls resulted in a loss of body mass, which was assessed against threshold parameters to determine reproductive failures and mortality. Group associations were then assessed and updated at the end of the daily cycle. We made the simplifying assumption that mass had energy content without partitioning that content into lean and fat tissue because (1) our objectives did not include killer whale body composition, or even precise consumption estimates, but rather predatorprey dynamics using energy as currency, (2) there were far larger uncertainties in thresholds and predation rates, and (3) relative to our population-level objectives, the metabolic submodel was simply part of the overall predatory efficiency of killer whales, changes in which had clear effects on the model output along a continuum of predator efficiency.

\section{Sensitivity and validation}

To evaluate the sensitivity of the model output to starting parameters and validate model behavior, conditions were set to the simplest scenario of a single prey population of 'Seals' (modeled after harbor seals), which was sufficiently large to support an average population of 200 to 300 killer whales (to minimize the effects of demographic stochasticity without generating long execution times). Williams et al. (2004) estimated that the average food requirements for a population of transient killer whales would be equivalent to roughly one harbor seal per day per adult killer whale. If we assume that the maximum net productivity of our 'Seals' occurs at $\sim 70 \%$ of equilibrium $(K)$ and that the growth rate is $\sim 80 \%$ of the maximum $(\lambda \approx 1.10)$, a population of 200 transient killer whales would require $>73000$ 'Seals' $\mathrm{yr}^{-1}$. For this to be sustainable with the assumed vital rates, a 'Seal' population of at least 730000 and a density-dependent equilibrium in excess of 1000000 would be required. Our single-prey test simulations therefore used a population of 'Seals' that would

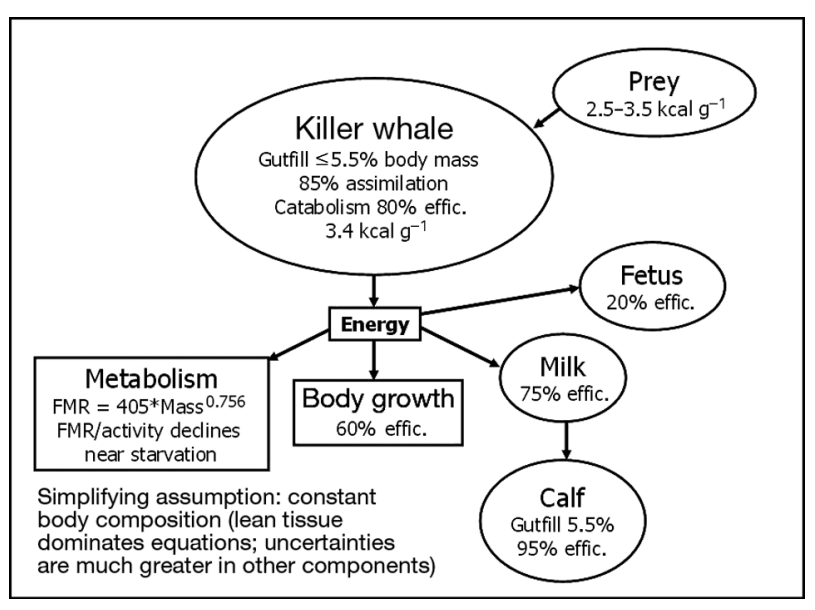

Fig. 2. Energetic model by which prey are converted into energy for metabolism, body growth, and reproduction of individual killer whales

equilibrate at $\sim 1400000$ in the absence of predation. Vital rates, density dependence, and predator encounter rate and vulnerability are specified in file prey1.csv (available in a downloadable package online; see the supplement). The model was allowed to run until both predators and prey experienced periods of growth, decline, and relative stability. The sensitivity of the relevant output variables to variation across plausible ranges of parameters was evaluated graphically while holding other parameters constant during multiple runs of 1000 yr. Model validity was assessed by concurrence of emergent population-level properties of the model killer whales with comparable properties reported in the literature. Specifically, the properties compared were maximum growth rates, age-sex composition, agespecific survival, pregnancy and calving rates (Olesiuk et al. 1990), prey consumption rates, and the size of hunting groups (Baird \& Dill 1995). We also attempted to evaluate the plausibility of model behavior under conditions of prey abundance or scarcity by comparison with other species of large mammals that have been reported in those conditions (e.g. the demography of irruptive ungulate populations or cyclic lynx Lynx canadensis suggest plausible demographic changes in response to food abundance/scarcity) (Fowler 1981, Gaillard et al. 1998, Eberhardt 2002).

\section{Three-prey scenario}

We used the single-prey model as a baseline to explore interactions between killer whales and multiple prey by calculating the expected amount of bio- 
mass provided by the addition of 2 new prey species to the model (number of prey $\times$ expected encounter rate $\times$ average vulnerability) and reducing the number of 'Seals' to remove a comparable biomass of those prey from the whales' diet. In this way, the addition of new prey species would lead to a similar standing stock of killer whales. Two species of possible interest are Steller sea lions, because of their threatened and endangered status in parts of their range, and gray whales Eschrichtius robustus because of their apparent importance as prey during a narrow window of time in the spring when calves are known to be preyed upon. Using these as templates, we chose to model more generalized alternate prey: a species occurring at lower numbers, 'Sea Lions', that might be affected indirectly by the dynamics of the predator and its primary prey, and 'Whales' that constitute potentially large prey biomass but are available only seasonally due to their migratory behavior and are most vulnerable as calves. 'Sea Lions' were assumed to be somewhat less vulnerable than 'Seals' and to require slightly larger killer whale group sizes for optimal foraging. 'Whales' were the least vulnerable and required group sizes of 5 or 10 adult killer whales to reach optimal hunting efficiency on calves and adults, respectively. Seasonal availability and increased hunting specialization on whales was simulated by limiting the window of time during each year to spring and summer (Days 120 to 300) and increasing their encounter rates over baseline rates for seals and sea lions. Parameters controlling the population dynamics and predator vulnerability of all 3 prey (prey3.csv) are available in the downloadable program package.

The potential for dynamic interactions among the predators and these 3 prey types was explored by increasing the encounter rate between killer whales and the seasonally available 'Whales' in comparison to 'Seals' and 'Sea Lions' in a set of computer experiments in which the starting populations were allowed to equilibrate for $200 \mathrm{yr}$, and their interactions were evaluated over the last 800 yr. Daily encounter probabilities between the predator group and individual prey were varied from equal $(4.0 \times$ $10^{-6}$ ) among prey to $20 \times$ the baseline for whale prey during the spring-summer period. Of interest was how increasing the importance of large whale prey might affect the population dynamics of all species involved across an experimental gradient in the hunting specialization on the seasonal whales. In addition, scenarios involving elevated encounters of large 'Whales' relative to smaller prey $(15 \times)$ were subjected to 2 perturbations: (1) the sudden reduc- tion of the stock of large 'Whales' by a catastrophic harvest and (2) a reduction in the carrying capacity of the main year-round prey base ('Seals') by $40 \%$ for a period of $20 \mathrm{yr}$ (a 'regime shift').

\section{RESULTS}

In general, many of the parameters chosen for inclusion in the model have values or likely ranges that can be supported with field data and allowed persistence of predators and prey. However, some parameters are poorly known (e.g. encounter rates), and their plausible ranges exceeded the narrow parameter space that allowed predators and prey to persist.

\section{Sensitivity and validation: single-prey scenario}

Encounter/attack rate

In classical predator-prey models, the attack rate, modeled here as the product of encounter rate and vulnerability, greatly affects the persistence of a single predator and single prey system (Metzgar \& Boyd 1988); low attack rates lead to steady decline and extinction of predators, while high rates lead to oscillations and the extinction of one or both species. Attack rates of transient killer whales in southeast Alaska (Dahlheim \& White 2010) suggest that daily encounter rates (probability that a particular group of killer whales would encounter a single individual prey) might be on the order of $10^{-4}$ to $10^{-6}$. For models with a single super-abundant prey, encounter rates producing relatively stable killer whale populations comprised a narrow range (Fig. 3) within the range of plausible values. For a set of fixed parameters, encounter rates of $<3.00 \times 10^{-6}$ led to rapid extinction of the killer whales, while increasing the encounter rate above this threshold led to increasing numbers of killer whales but also to oscillatory behavior above $4.00 \times 10^{-6}$ (Fig. 3). The actual values needed to produce this progression varied with the choice of values for other parameters (e.g. greater energetic efficiency could lower the values of encounter rates needed for stability, or lower energetic efficiency could lead to extinctions), but a narrow range of encounter rates needed for relatively stable numbers of killer whales was characteristic of all simulations. The low number of reproductive killer whales and simplistic assumptions about random encounters undoubtedly contribute to model instabil- 

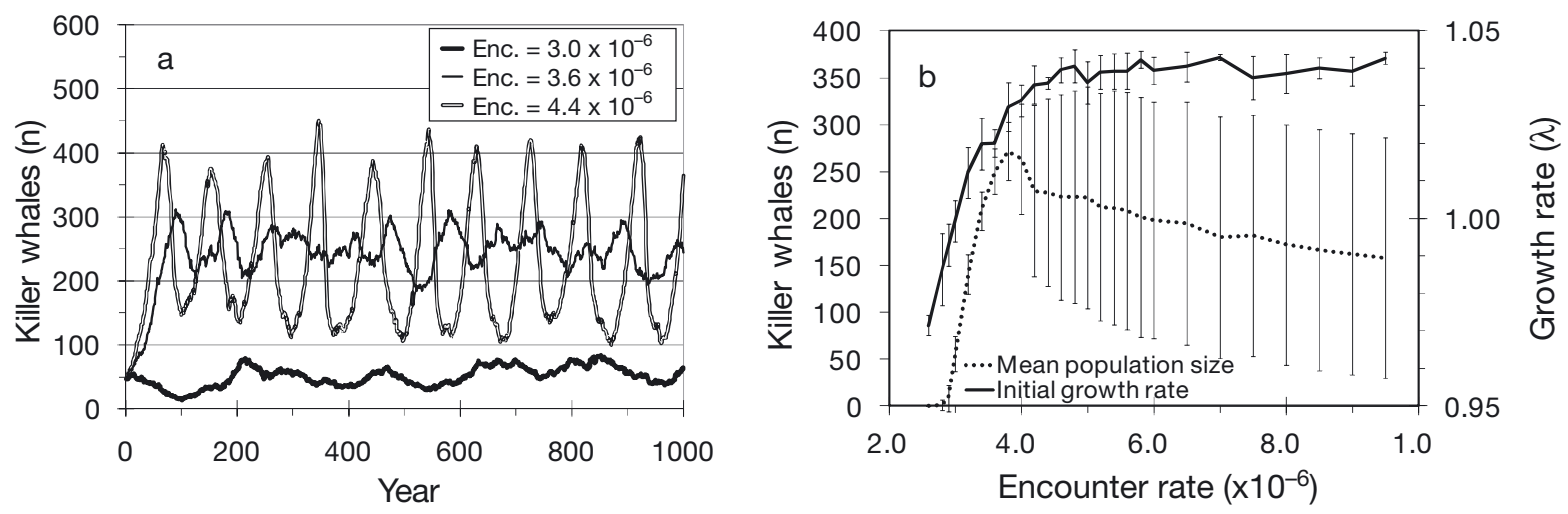

Fig. 3. Orcinus orca. (a) Three trajectories for different assumed encounter rates between hunting groups of killer whales and individual prey. (b) Initial (maximum) growth rate of the killer whale population in the first 50 yr of simulations and mean $( \pm$ SD) abundance of killer whales in years 200 to 1000 in relation to encounter rates (5 replicate simulations each), illustrating the effects of increasing predator efficiency on basic killer whale population dynamics

ity as encounter rates increase. Nevertheless, as a first approximation of how killer whales might interact with prey, we determined a range of encounter rates that allowed the persistence and relative stability of killer whale populations as a necessary precondition for assessing other model parameters.

Thresholds, gut size, and energetic efficiencies

Many of the remaining parameters in the model are expected to have redundant effects on model performance. For example, energetic efficiencies are part of a chain of conversions, any one of which could be used to lower or raise the overall efficiency with which prey are converted into predator biomass. The real caloric value of the prey, including different costs of capture, should have an inverse effect on the number required to sustain a model killer whale. Similarly, several thresholds set for killer whale mass relative to target mass influence the birth and age-specific survival rates and are therefore likely to affect population recruitment and growth. Our implementation includes some redundancy in function relative to the objective of simulating predator-prey dynamics. We therefore tested the sensitivity of certain model output variables in relation to plausible variation in model parameters, but we ignored parameters whose action duplicated the effect of others (e.g. efficiency of milk production, milk energy content, and calf digestive efficiency all have similar effects on energy transfer from mother to calf) or obviously had small influence (e.g. birth mass alters both fetal and calf growth trajectories but with little expected influence on mortality). We focused on (1) thresholds of body mass (as a proportion of target mass) for abortion, cessation of lactation, and starvation, (2) gut size as a constraint to daily consumption, and energetic efficiencies of (3) producing milk and (4) digesting prey. Each of the parameters was evaluated graphically for its effect on maximum population growth rate and asymptotic number of killer whale numbers from identical starting conditions in simulations of $1000 \mathrm{yr}$ for each value of the parameter. Where a likely demographic mechanism for the effect of a changing parameter value was apparent (e.g. decreasing efficiency of milk production is expected to decrease neonate survival), the mean value of the appropriate vital rate was also graphed against the value of the parameter. The results are summarized in Fig. 4 for 6 parameters.

The threshold body mass (as a proportion of agespecific target mass) that caused a pregnancy to be aborted caused little effect when set near the starvation threshold (0.7 to 0.72 ), but it led to a lowered calving rate at 0.74 and rapid extinction of the killer whales by 0.80 of target mass. The threshold for cessation of lactation and therefore death of neonates was also influential, with a nearly linear effect on neonate survival from just above that causing death of the mother $(0.70)$ to complete mortality of neonates and extinction of killer whales at a threshold of 0.80 . The default threshold was selected to be 0.75 , which produced neonate mortality from birth to the first summer similar to that reported by Olesiuk et al. (1990) while making it responsive to variable adult consumption rate in the models. Increasing efficiency of milk production had a positive effect on calf survival at all levels but little effect on equilibrium population size for values $>0.5$ (Fig. 4e). Starvation thresholds lower than the default of 0.7 had little 

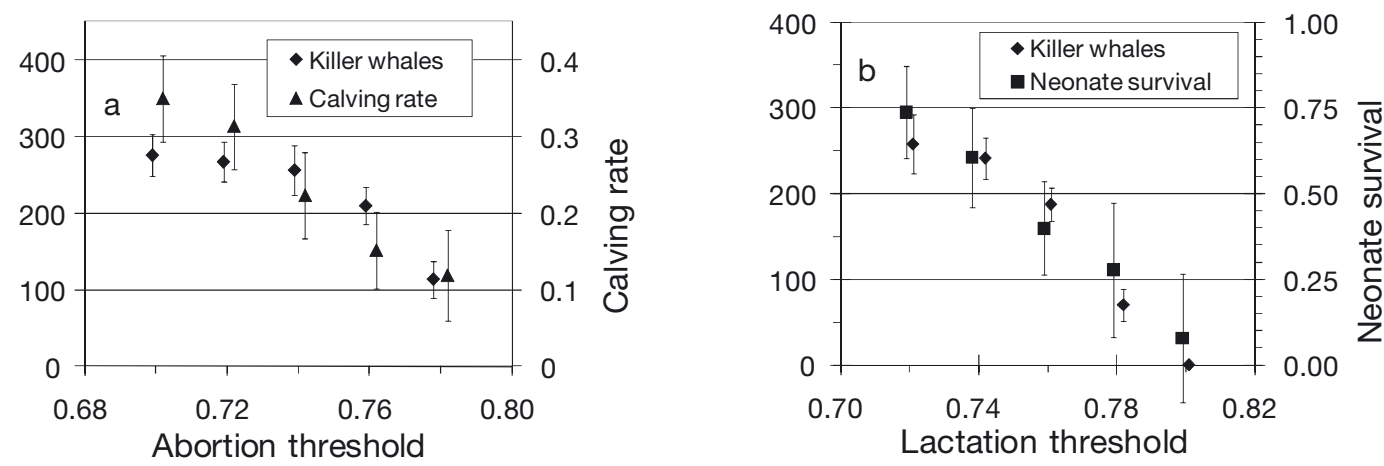

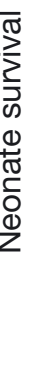
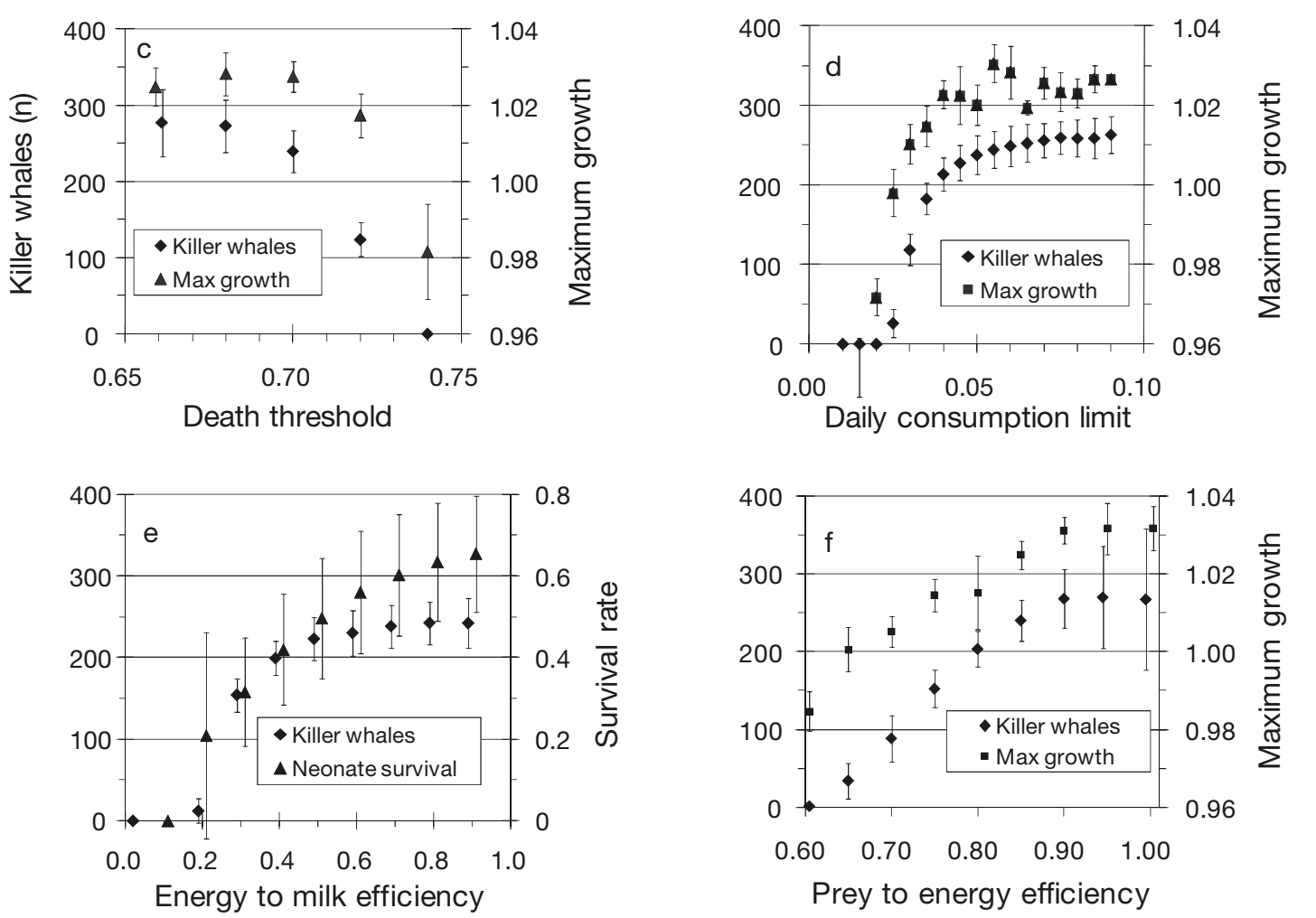

Fig. 4. Sensitivity of killer whale numbers in the final $800 \mathrm{yr}$ of $1000 \mathrm{yr}$ simulations and other key output variables in response to varying key input parameters (5 replicate simulations each, error bars are SD). (a) Thresholds at which killer whales aborted pregnancies, (b) stopped lactation, and (c) died are expressed as a proportion of age-specific target mass, as is the (d) daily consumption limit. (e) Metabolic efficiencies of milk production and (f) prey conversion to energy are compared to neonate survival and maximum population growth rate, respectively

effect on equilibrium killer whale numbers, but higher thresholds led to lower population growth rate, lower numbers, and extinction by a threshold of 0.74 . Population growth rate and equilibrium level were little affected by daily consumption limits $>0.04$ of the target mass (Fig. 4d), and 0.055 was used as the default.

The metabolic efficiency of converting prey to energy (Fig. 4f) encapsulates the effect of any link in that energetic chain and demonstrated a strong effect on the total number of whales that could be sustained and on the stability of whale numbers as efficiency was increased. It is very similar in functional form to that of encounter rates (Fig. 3). The particular functional shape illustrated in the figure could be shifted in either horizontal direction by changing some other parameter affecting the metabolic or hunting efficiency of the killer whales, but the progression from smaller to larger populations and toward more unstable population asymptotes with increasing efficiency was consistent. However, the results shown should not be interpreted as supporting a particular assumed metabolic efficiency or rate, most of which are uncertain. 


\section{Group size}

We evaluated whether model killer whale groups approximated the expected optimum group size when we altered the shape of functions relating prey vulnerability to group size. We chose parameters to create modal values of 2, 3, 4 and 5 for the test case of superabundant 'Seals' (Fig. 5a,b). The optimizing models were based on 'adult equivalents' (downgrading juveniles for their expected lesser effectiveness), while the model output included all individuals, so we expected the observed group size might exceed the modal optimum, but group sizes were constrained by the available groups of related whales with which each group (including 'groups' of 1) might merge. The logistic functions relating killer whale group size to maximum vulnerability of prey (Fig. 5a) produced shapes of the killing rate per killer whale (Fig. 5b) that were unimodal at the optimum group size. Adjusting the shapes of the vulnerability and killing rate curves altered the overall killing rates and resulting equilibrium population size of killer whales, so the simulations were standardized (by altering the encounter rates) to produce killer whale populations that varied around 200 whales in the last $800 \mathrm{yr}$ of $1000 \mathrm{yr}$ runs (Fig. 5c). The mean group size was close to the modal optimum size expected in the 4 test cases, and the histogram of daily observed group sizes for an optimum group size of 3 (Fig. 5d) was plausible when compared to those reported by Baird \& Dill (1996). Mean group size was larger by 0.2 to 0.9 whales during the initial population growth phase of the simulations, but this effect incorporates complex relationships of motheroffspring association rules and skewness of the per capita consumption to group size curves, so the effect was not quantified in a precise way. Further details of group formation and sensitivities to underlying parameters are given in the supplement at www.intres.com/articles/suppl/m466p275_supp.pdf.

\section{Population dynamics of model killer whales}

A representative simulation of killer whales preying on a superabundant population of 'Seals' was analyzed to evaluate whether killer whale population dynamics conformed to those found in resident killer
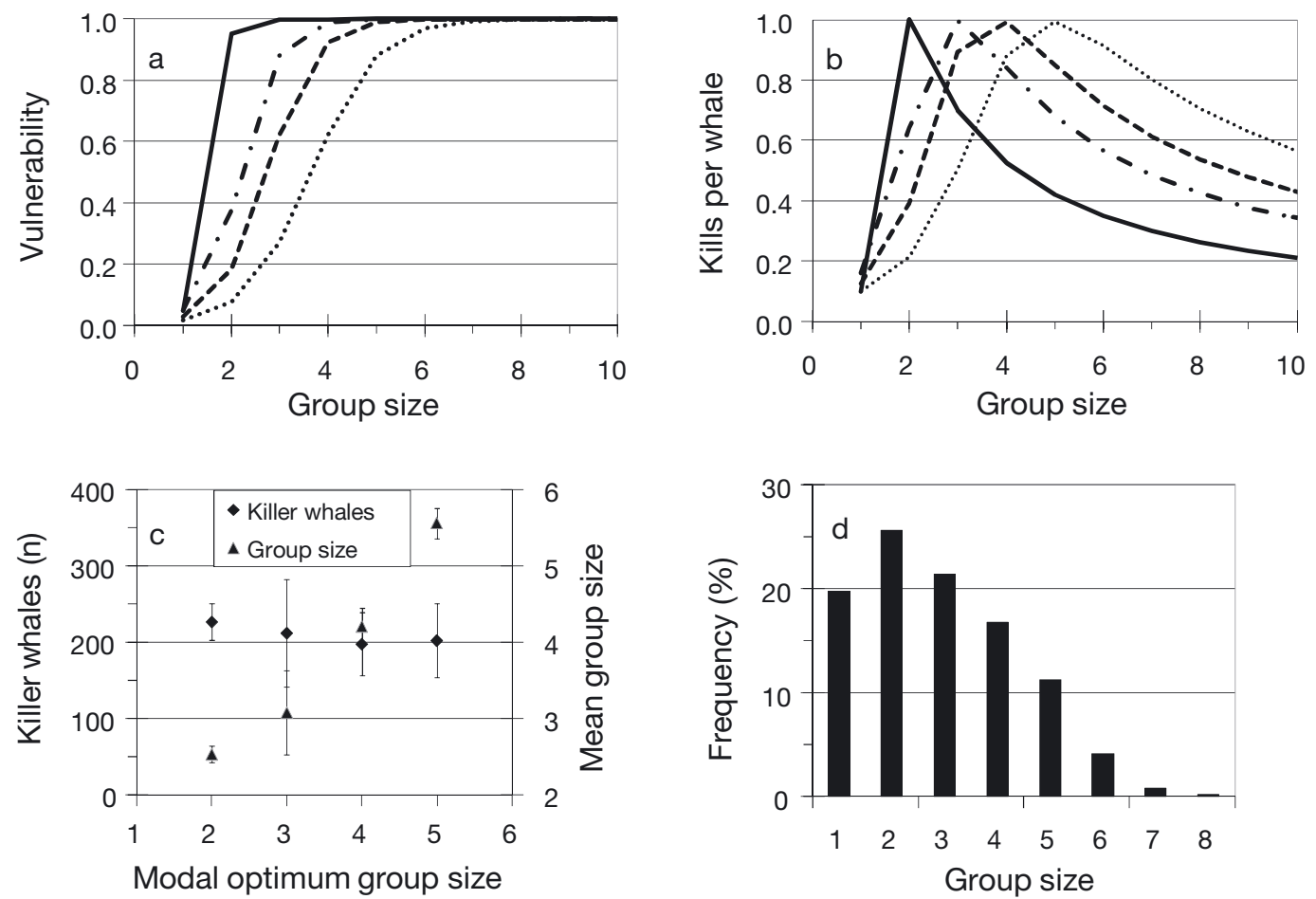

Fig. 5. (a) A family of 4 logistic functions relating killer whale group size to a maximum vulnerability (probability of killing given an encounter) of prey. These encounters produce (b) expected payoffs in consumable prey per group member, which are scaled to the maximum value with line patterns to match the curves in (a). (c) Vulnerability simulations of 1000 yr with encounter rates scaled to produce roughly the same numbers of killer whales in the last 800 yr of each run, demonstrating that mean group size approximates the modal optimum group size. (d) A histogram of group sizes for a modal optimum of 3 killer whales, demonstrating the variability in daily group size 
whales (Olesiuk et al. 1990) and large mammals in general (Fowler 1981, Eberhardt 2002, Gaillard et al. 1998). Parameters where chosen to produce a population with periods of growth and decline (i.e. dynamic behavior) so attendant changes in vital rates and consumption could be evaluated. There are no demographic data from field populations of killer whales that can encompass the period and the range of growth rates simulated. Olesiuk et al. (1990) estimated a life table of resident killer whales with a stable population growth rate of $\lambda=1.03$. A stable projection from that table produced similar age-class composition and survival rates to those of the initial growth phase in our agent-based simulations, with some differences in calving rate and calf survival that had offsetting effects on the growth rate (Table 1).

The trajectories of killer whale and harbor seal abundance in a typical simulation where both populations fluctuate are shown in Fig. 6. From an initial population of 50, the killer whale population grew at an annual rate of just over $\lambda=1.03$ in the first $50 \mathrm{yr}$, reaching a peak of 280 after $66 \mathrm{yr}$ and fluctuating
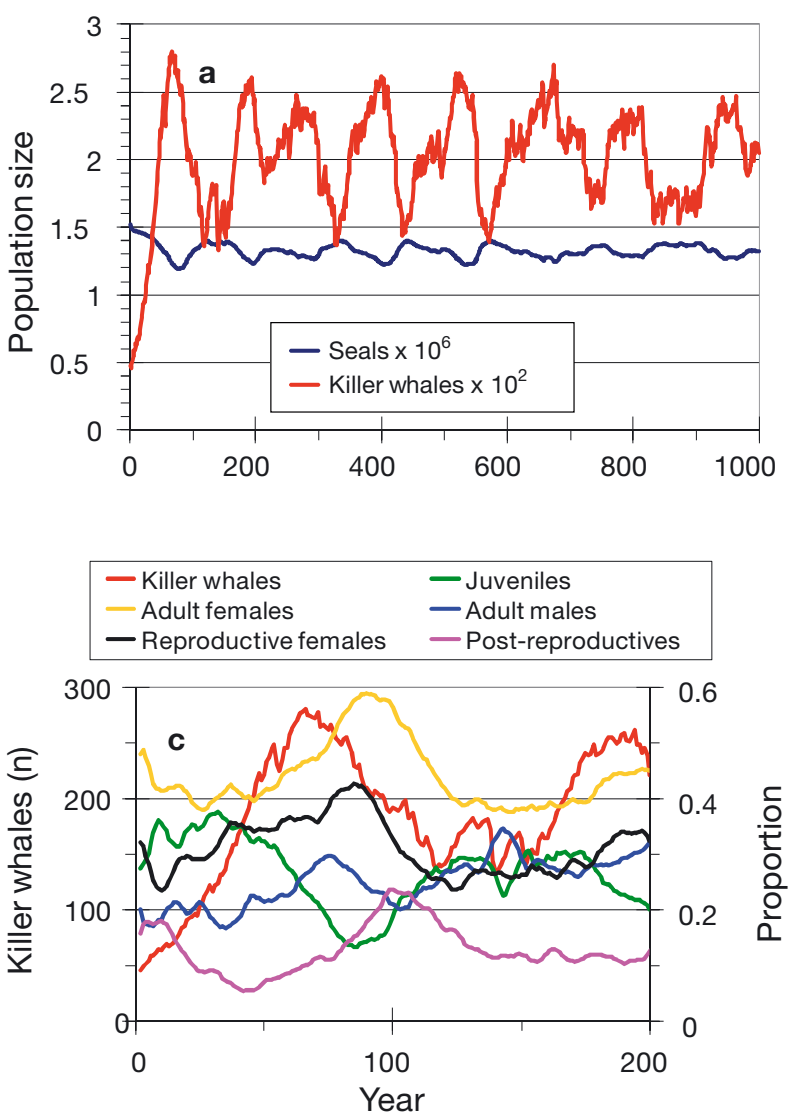

Table 1. Orcinus orca. Comparison of age structure and survival from agent-based simulations (standard deviation in parentheses) during $50 \mathrm{yr}$ of growth to those of a stable population estimated from a life table of resident killer whales (Olesiuk et al. 1990) growing at a comparable rate

\begin{tabular}{|lcl|}
\hline & $\begin{array}{c}\text { Stable } \\
\text { projection }\end{array}$ & $\begin{array}{c}\text { Agent-based } \\
\text { simulation }\end{array}$ \\
\hline Growth rate $(\lambda)$ & 1.029 & 1.032 \\
Females $>10 \mathrm{yr}$ & 0.40 & $0.40(0.03)$ \\
Males $>10 \mathrm{yr}$ & 0.24 & $0.20(0.04)$ \\
Juveniles 1-10 yr & 0.30 & $0.34(0.03)$ \\
Calves & 0.04 & $0.06(0.02)$ \\
Adult female survival & 0.989 & $0.987(0.020)$ \\
Adult male survival & 0.969 & $0.966(0.051)$ \\
Juvenile survival & 0.952 & $0.967(0.037)$ \\
Calf survival & 0.96 & $0.895(0.152)$ \\
Calving rate (10-40 yr) & 0.14 & $0.18(0.07)$ \\
& & \\
\hline
\end{tabular}

between 135 and 270 for the remainder of the $1000 \mathrm{yr}$ simulation. Periods of decline were marked by reduced calving rates and juvenile survival in comparison to periods of increase, leading to poor adult

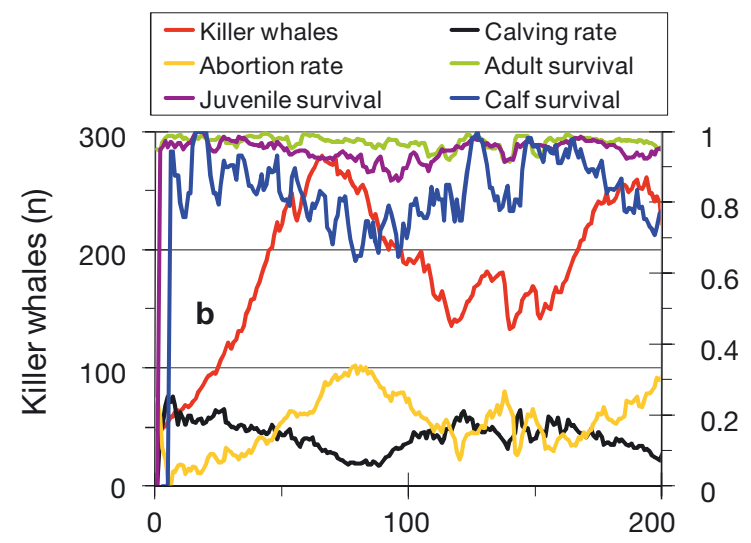

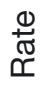

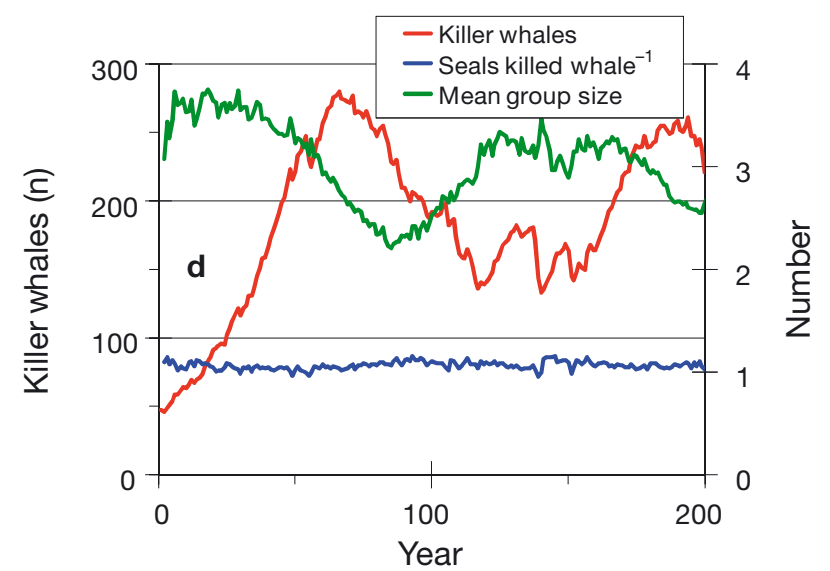

Fig. 6. A typical simulation of transient killer whales and a superabundant, single prey population of 'Seals' showing (a) fluctuating population size of predators and prey over $1000 \mathrm{yr}$, (b) changing vital rates (5 yr running averages), (c) age-sex structure, and (d) mean hunting group size and daily consumption rates for the first $200 \mathrm{yr}$ 
recruitment and shifts in age-sex structure that persisted for decades (Fig. 6). These long-term age structure fluctuations, if representative of killer whales in the wild, would be consistent with the high stability of adult survival and the species' extreme longevity but would probably be unique to large predators. These features could also be expected to lead to substantial lags in predator numeric response to prey abundance, and unstable predator-prey interactions on long time scales. This was observed in the illustrated $1000 \mathrm{yr}$ time series (Fig. 6), in which the mean lag between clear troughs in prey and predator numbers was $31 \mathrm{yr}$ ( $\mathrm{n}=5$, range 16 to 38 ).

\section{Consumption-dependence and predator-prey dynamics}

The daily consumption of 'Seals' per killer whale ranged from 0.95 to 1.16 (mean $=1.07$, standard deviation $=0.04$ ), similar to other estimates of killer whale consumption (e.g. Baird \& Dill 1996, Williams et al. 2004), but that result masks the variation in vulnerability and consumption of juvenile and adult prey and the differing metabolic requirements between age classes of killer whales (Table 2). Variation in per capita consumption, as reflected in high coefficients of variation (CVs) (Table 2), was higher in the younger age classes, as would be expected when a higher proportion dies of starvation. If we assume that most density-dependent changes in vital rates are driven by consumption, then what are often thought of as density-dependent responses in vital rates are more usefully analyzed as consumptiondependent responses in vital rates that control the abundance of predators. We expected these responses to adhere to density-dependent patterns in that juvenile survival and reproductive rates should be the most responsive to changes in the per capita prey consumption rates of killer whales, as in other large mammals (Eberhardt \& Siniff 1977, Gaillard et al. 1998, Eberhardt 2002, Rotella et al. 2012). This expectation was confirmed by a high degree of consumption-dependence ( $p<<0.05$; Fig. 7) in juvenile survival and apparent calving rate (recognizing that the rates of abortion and neonate mortality are confounded in model and field observations of apparent calving rate). These relationships drove the strong shifts in recruitment and changing age structure apparent in the trajectories of Fig. 6.
Surprisingly, the finite growth rate $(\lambda)$ was negatively correlated with the total per capita consumption rate (Fig. 7). This counter-intuitive result was due primarily to changes in population age structure as the population fluctuated in size (Fig. 7). The highest consumption rates occurred when juvenile recruitment was low, leading to a high proportion of adults whose larger body size required greater consumption. This resulted in high rates of per capita consumption while reproductive potential and population growth rate were relatively low and senescent mortality was increasing. This is an intriguing aspect of the predator-prey relationship for transient killer whales that suggests caution when looking for killer whale functional or numeric responses to prey abundance. Functional and numeric responses of killer whales to prey density were, at best, weakly correlated to prey density or prey density per killer whale when considered without time lags. When time lags were considered, the strongest responses were to prey abundance directly rather than to prey available per killer whale (i.e. model killer whales were more 'preydependent' than 'ratio-dependent') (Arditi \& Ginzburg 1989), but the amount of variation explained by prey density was small $\left(\mathrm{r}^{2}<0.16\right.$; Fig. 8). Both the time lags and the negative correlation between prey density and killing rate might contribute to instability in the predator-prey relationship. Such simulations suggest that, with the broad range of age-specific body sizes and reproductive potentials possible with killer whales, the standing age and social structure may be more important for interpreting killer whale impact on their prey, and predator-prey dynamics in general, than killer whale numbers per se.

\section{Three-prey scenario}

The simulated 3-prey community included superabundant 'Seals', as in the single-prey model, a 


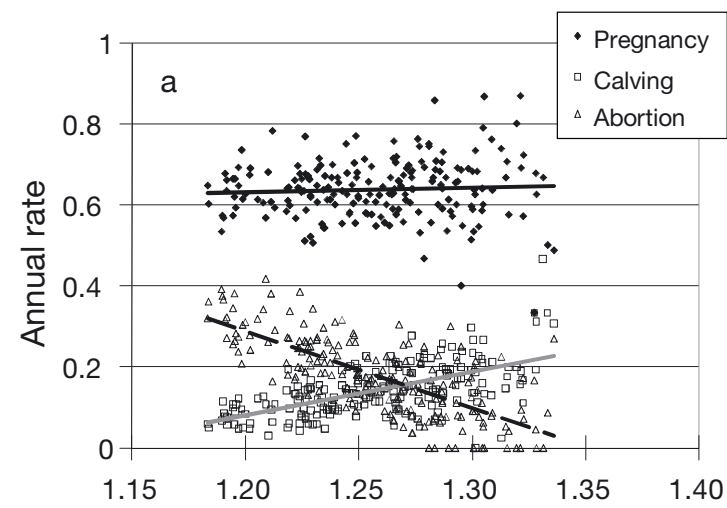

Seals eaten adult whale ${ }^{-1} \mathrm{~d}^{-1}$

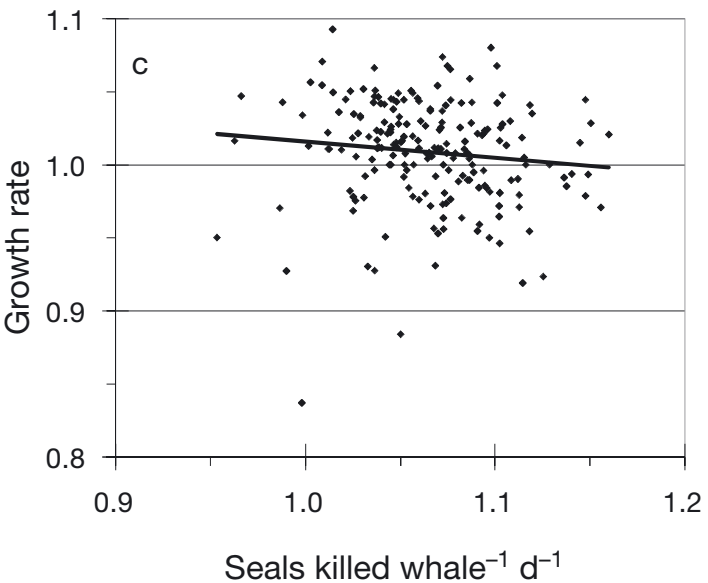

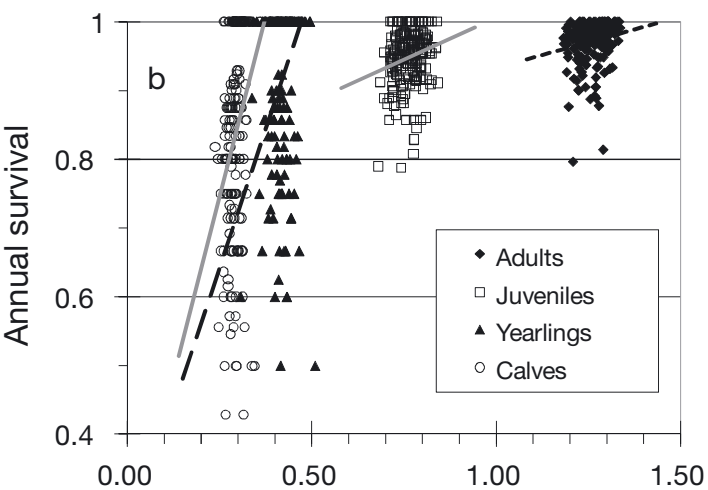

Seals eaten whale $\mathrm{e}^{-1}$

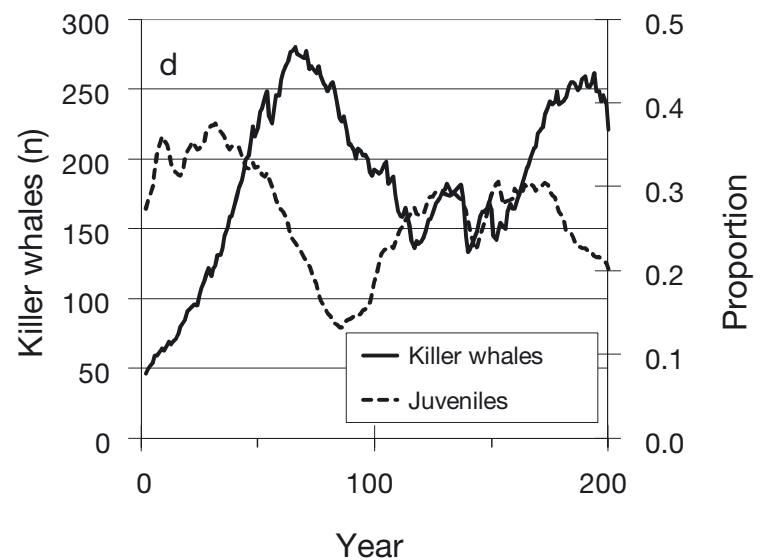

Fig. 7. Scatterplots from the first $200 \mathrm{yr}$ of a simulation of killer whales preying on a single, superabundant prey population of 'Seals': (a) calving rates were positively and abortion rates negatively correlated with the number of 'Seals' eaten per adult (>10 yr old) killer whale per day; (b) annual survival rates were positively correlated with class-specific consumption, but (c) finite population growth $(\lambda)$ was negatively correlated with total per capita killing rate due to (d) shifting age/size structure during population fluctuations (see 'Consumption-dependence and predator-prey dynamics')
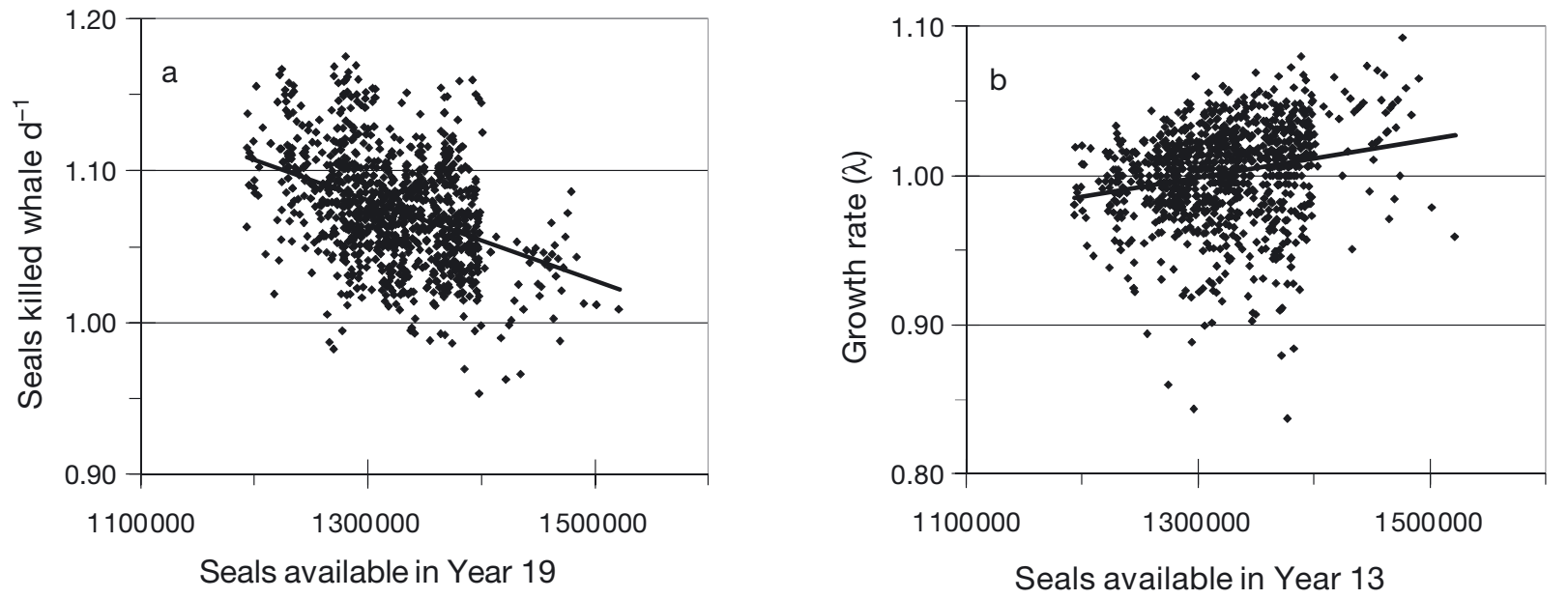

Fig. 8. (a) Functional and (b) numeric responses of killer whales to prey abundance were more dependent on absolute abundance than the 'Seals':killer whales ratio, with anti-regulatory properties indicated by long time lags and the negative slope of the functional response 
small population of generic 'Sea Lions', and a large population of large 'Whales' consistent with their being a signifcant portion of the multispecies community of whales believed to occur in the eastern North Pacific Ocean prior to commercial whaling (Pfister \& DeMaster 2006). Simulations were run with $200 \mathrm{yr}$ allowed for growth of a small population of killer whales and $800 \mathrm{yr}$ of relative equilibrium to evaluate the emergent dynamics. Encounter rates between killer whale groups and prey were initially the same for all prey, but Whales were only available for $180 \mathrm{~d} \mathrm{yr}^{-1}$ to mimic the seasonal availability of migratory large whales that might be typical in the North Pacific, and adult Whales were specified to have much lower vulnerability than calves. However, the lower numbers and vulnerability of the large Whales in comparison to the superabundant Seals led to very little predation on Whales. To increase the potential importance of Whales to killer whales, we simulated a range of increasing encounter rates between killer whale groups and Whales to mimic behavioral specialization on the larger prey when they were available, as appears to occur in some areas (Barrett-Lennard et al. 2011). Even with very high specialization on the seasonal Whales, there was only a moderate increase in the equilibrium levels of killer whale population size and predation rates on Seals and Sea Lions, even to the point where the large Whale population was driven to extinction (Fig. 9). The daily time step of the model ensured that nearly all (98 to $100 \%$ ) of the smaller Seals and Sea Lions killed were also consumed, while only $\sim 7 \%$ and $13 \%$ of adult and calf Whales were consumed, respectively.

From these initial 3-prey simulations, we chose encounter parameters so that all 3 prey species were reduced relative to a predator-free equilibrium and performed 2 perturbations: (1) after initial equilibration of predators and prey, we imposed a heavy harvest beginning in Year 300 of 56000 Whales over $20 \mathrm{yr}$ from a population with a carrying capacity of $\sim 80000$ and allowed the system to recover and equilibrate, then (2) in Year 600 we reduced the carrying capacity of Seals by $\sim 40 \%$ over a period of $3 \mathrm{yr}$, sustained that 'regime shift' for a period of $14 \mathrm{yr}$, and returned the system to its starting parameters over $3 \mathrm{yr}$, continuing the simulations to Year 1000. These 2 sequential experiments were replicated 10 times. Mean values of killer whales and their prey (Fig. 10) show the typical increase in killer whales and the reduction of prey populations as killer whale numbers increased in the first $100 \mathrm{yr}$. The effect of removing roughly half of the 'Whales' beginning in Year

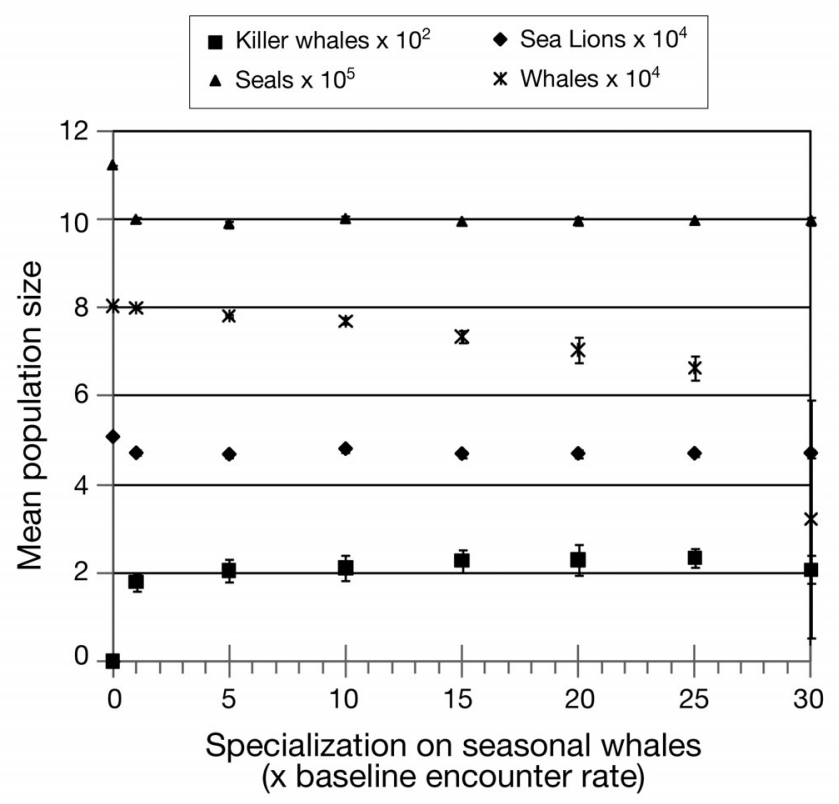

Fig. 9. Mean population size of killer whales and 3 generic prey ('Seals', 'Sea Lions', and large 'Whales') over 800 simulated years after initial $200 \mathrm{yr}$ equilibration period with increasing specialization on seasonally occurring large whale prey. The baseline encounter rate between any individual prey and a killer whale group is $4.0 \times 10^{-6}$. Prey population size in the absence of predation is shown on the $y$-axis. Error bars are $\pm 1 \mathrm{SD}$

300 was not discernable in individual runs, but the mean effect showed a slight decline in the alternate prey and small decline in juvenile killer whale recruitment, followed by a small decline in killer whale numbers. As modeled, Seals represented a large prey base (which might represent a conglomeration of multiple species with similar size and life histories) and dominated the effect on killer whale population dynamics. The sudden precipitous decline of Seals in Year 600 caused a sharp decline in killer whale numbers that reached its nadir $54 \mathrm{yr}$ after the onset of the regime shift and $\sim 30 \mathrm{yr}$ after the carrying capacity for Seals had returned to its original condition (Fig. 10). This was caused primarily by the collapse in killer whale recruitment for most of that $20 \mathrm{yr}$ period of decreased Seal availability. A small but positive indirect effect of the Seal decline was evident in the numbers of alternate prey during the period of low killer whale numbers.

\section{DISCUSSION}

Our overall objective of producing an ABM with emergent properties similar to those that have been estimated from live killer whales was met, and some 

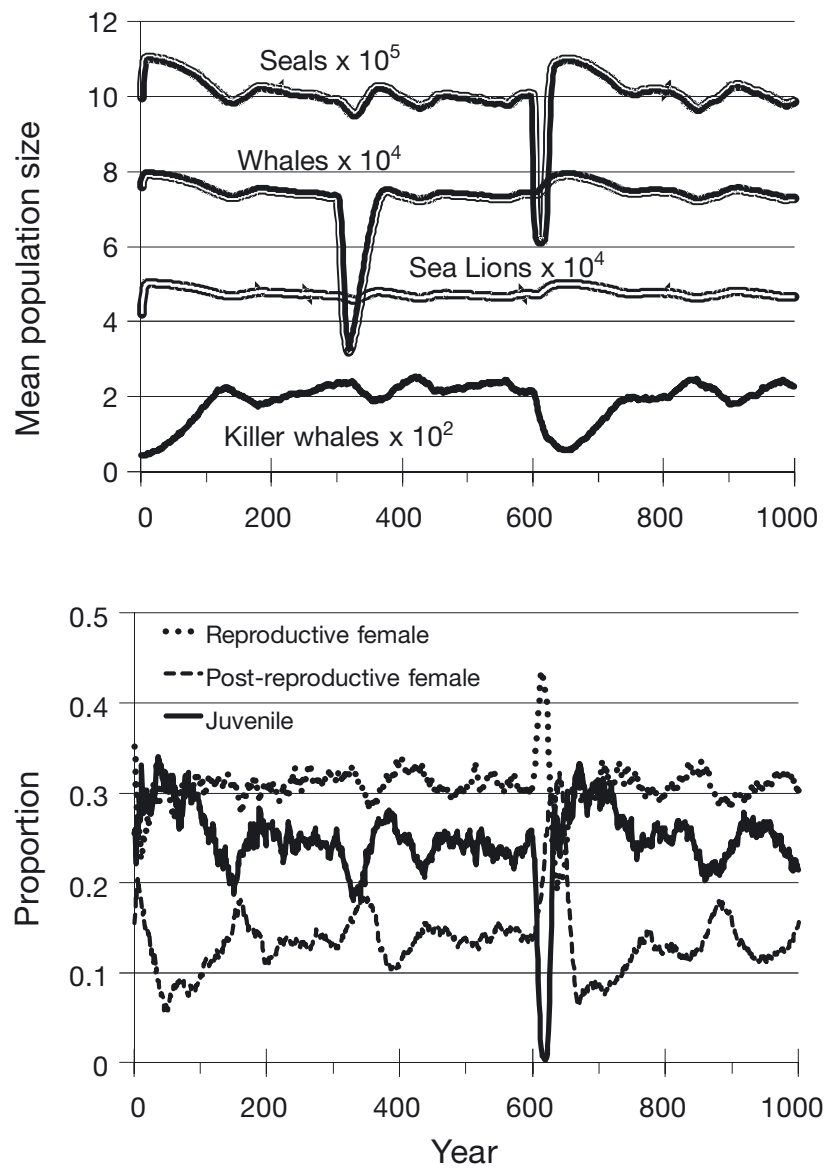

Fig. 10. (a) The mean population size of killer whales and 3 generalized prey populations from 10 simulations of $1000 \mathrm{yr}$ duration in which the populations are first allowed to reach an equilibrium, then whale prey are removed by harvest for 20 yr beginning in year 300 , followed in year 600 by a reduction in the carrying capacity of the dominant prey by $\sim 40 \%$.

(b) Shifts in age structure of the killer whale population

non-intuitive properties of those models were discovered. Rates of prey consumption were (not surprisingly, given their shared derivation) similar to those published (e.g. Barrett-Lennard et al. 1995, Baird \& Dill 1996, Williams et al. 2004), but population-level variation in per capita consumption was dependent on the age structure of the killer whales (Williams et al. 2011). Demographically, baseline vital rates were easily adjusted to mimic those expected under exponential growth, while energetic and growth submodels produced plausible responses in vital rates when prey became scarce. Confirmation that such changes occur at the population level in transient killer whales is difficult to obtain, but the use of an ABM might identify other indirect properties that could strengthen an argument that food shortages affect the demography of transient killer whales. Confidence in agent-based simulations would in- crease with better estimates of the input parameters used here and validation or improvement of the submodels. For example, the existence of thresholds in body mass that lead to decreasing lactation or reproductive failure might be estimated in captivity, while field studies would be unlikely to obtain sufficient sample sizes to definitively link consumption to these mechanisms. In field studies, attempts to link prey abundance or consumption to focal killer whale groups might examine group size and composition when interpreting prey consumption rates and may be able to validate or improve on the foraging assumptions and rules of group formation used here.

Many other results, particularly those pertaining to long-term predator-prey dynamics, are speculative but are rich in detail about possible mechanisms and consequences. There are essentially no theoretical models applicable to a single predator and the number of prey routinely taken by transient killer whales or to a predator with such longevity and likely demographic inertia. The potential importance of standing age structure to the interpretation of demographic trends in killer whales was amply illustrated in model simulations. In some cases, the prey population began its recovery over $30 \mathrm{yr}$ before that of the killer whale population, and the numbers of killer whales sometimes remained stable for decades into a prey decline before dropping. Often, the lowest level reached by killer whales occurred after the prey had completely recovered in numbers. The model effectively assumed strong age dependence in the relationship of prey consumption to vital rates that are typical of large mammals (Eberhardt \& Siniff 1977, Gaillard et al. 1998, Eberhardt 2002), but it is possible that killer whales are an exception (Ford et al. 2010), and more data are needed on these relationships. Our strong age structure changes might be dampened if, for example, calves and juveniles are given strong priority when sharing prey in hunting groups (Hoelzel 1991).

Upper trophic level predators, including killer whales, are often cited as potential indicators of ecosystem processes (Piatt et al. 2007, Ford et al. 2010), but the simulations here suggest that interpreting killer whale behavior and demographics as such an indicator may be a subtle task. The ability to determine age- and sex-specific demographic rates and age structure in killer whale field studies is essential to understanding population productivity and other potential responses to changing prey communities and their availability to killer whales. In simulations, this was largely due to the sensitivity of calving rate and juvenile mortality to consumption, the narrow 
age window for reproduction, and the existence of a significant post-reproductive class in killer whale populations. The predator-prey dynamics that follow from this do not lend themselves to classical forms of predator-prey models, though the output from agentbased simulations may aid in developing simpler mathematical models with long time lags.

In fish-eating resident killer whales, short-term effects of prey scarcity were seen on the reproductive and survival rates of resident killer whales off British Columbia (Ward et al. 2009, Ford et al. 2010). The magnitude of changes in those studies suggest that potential perturbations, and therefore time lags, may be smaller than in our simulations, but even in that comparatively long study, the time series is too short to evaluate long time lags and age structure perturbations, particularly with the study population clearly in a growth phase for most of that study. Moreover, the fluctuations in prey abundance observed in those studies were not known to be caused by killer whale predation, and the population dynamics of the prey (chinook salmon Oncorhynchus tschawytscha) would not be expected to have the inertia of long-lived marine mammal prey. Differences in prey life histories, their exploitation by humans, and intrinsic population dynamics might lead to very different predatorprey dynamics in resident fish-eating and transient mammal-eating killer whales.

Current controversies about the role of transient killer whales in the decline of species such as Steller sea lions and harbor seals have taken little account of the reciprocal effect such declines might have on the abundance of killer whales. The simulations performed here indicate that such effects could be profound and suggest some attendant changes that might be relevant to future studies. One is that there may be long lags in the numeric response of killer whales following prey reduction: reduction of prey numbers might increase the impact of killer whale predation and accelerate a prey decline until the effects of reduced recruitment and shifting age structure act to decrease killer whale numbers. The practical significance of this is that the first detectable effects of reduced prey populations may be more likely to be found in the age/sex structure of transient killer whales and class-specific vital rates, and these are probably measurable with current methods at the population or social group level, even while total numbers of killer whales appear relatively stable. Similarly, changes in numbers of killer whales cannot be interpreted without information on the age/sex structure because they could be either a response to immediate conditions or a legacy of some event that occurred decades before. In simulations, the per capita consumption rate varied with age structure and recruitment success, which also could affect assessments of the impact of transient killer whales on prey populations. Estimates of individual metabolic requirements should be weighted by the actual age/ sex structure (Williams et al. 2011), not simple estimates of average killer whales (Williams et al. 2004) or a calculated stable structure (Barrett-Lennard et al. 1995) that may be uncommon in such a long-lived species.

\section{Future directions}

Our intention was to implement an ABM built on biological components that have empirical support and to explore the emergent properties of models based on these biologically realistic elements. Uncertainties about the likely value of many parameters are important to those properties, but assumptions about the model structure also need to be addressed in the future. We feel that the most obvious and important of these is the simplifying assumption that hunting groups of killer whales and their prey encounter each other at random, without spatial structure and with very little temporal structure. The various species on which transient killer whales prey have widely different dispersion across the range of a given killer whale stock as well as pronounced differences in habitat use. Strictly speaking, it is impossible for a killer whale group to daily traverse a small part of its range and have the same probability of encountering, say, a Steller sea lion and a large whale every day of the year. Basing the predatorprey interaction on established theoretical assumptions allowed both for useful comparisons to conclusions from theoretical ecology and for segue into spatial models in the next generation of a killer whale ABM. The natural spatial implementation would be a spatial grid (hypothetical or one based on GIS maps) that incorporates information on the dispersion of prey stocks. The probabilistic mechanisms of encounter between groups of transient killer whales and between those groups and prey are much more plausible at smaller spatial scales, and a variety of decision mechanisms could be implemented and tested against the movement patterns inferred from resighting data or satellite telemetry. Spatial segregation of prey is a plausible mechanism providing potential for refuges and aggregation for prey species, factors that tend to prevent prey extinction and increase model stability in simpler predator-prey 
models (Hassell 1981, Akcakaya 1992, McCauley et al. 1993).

A second important area of development is in the range of population structure and dynamics of the prey. Simulations were performed with more than 3 prey species, but in the absence of prey-switching mechanisms beyond the hunting group size and efficiencies that were included, additional species tended only to mirror the dynamics of the dominant (most consumed) species. Greater realism in age/ sex-structure and age-specific reproduction of prey would likely lead to greater de-coupling of the population dynamics of different prey, a factor likely to be even more important when accompanied by greater spatial realism and more potential for effective preyswitching.

\section{CONCLUSIONS}

We do not intend to imply specific predictive ability to the model described here. Its value is primarily heuristic, and the lessons are general. Mechanisms of interaction between transient killer whales and their prey could be simulated and altered, and the logical consequences of such changes in our conceptualization could be observed. The model often suggested responses to changes that we might not at first predict, suggesting measurements we could make in the field to detect demographic or ecosystem changes. Changes in age structure and extreme lags in predator numeric changes are 2 such responses to declining prey abundance suggested by the model. To the extent that energetic requirements of transient killer whales are adequately captured in the model, we might expect that changing consumption patterns might cause changing demographic patterns, and simulations can suggest what data to collect to detect these responses. Our experience in developing and experimenting with these models has been a positive one of being forced to examine the details of physiological and ecological processes from their first assumptions to logical consequences that follow. Even where realism is stretched to breaking, we believe that our understanding of how real systems work can only be improved by such exercises. Our primary hope is that students of killer whale ecology will find a useful tool herein and be stimulated to use and improve on this beginning.

Acknowledgements. We thank C. Matkin, L. BarrettLennard, P. Wade, J. Durban, M. Dahlheim, J. Burns, D. Spalinger, and D. Siniff for helpful conversations during the creation of the model and absolve them of any responsibility for its shortcomings. We are grateful to L. Fritz, D. DeMaster, R. Williams, and an anonymous reviewer for helpful comments on the manuscript. We also thank the Marine Mammal Commission (www.mmc.gov) for funding student support for this project, the National Marine Mammal Laboratory for support to J.W.T., and University of Alaska Anchorage for support to K.J.M.

\section{LITERATURE CITED}

Akcakaya HR (1992) Population cycles of mammals: evidence for a ratio-dependent predation hypothesis. Ecol Monogr 62:119-142

Arditi R, Ginzburg LR (1989) Coupling in predator-prey dynamics: ratio-dependence. J Theor Biol 139:311-326

- Baird RW, Dill LM (1995) Occurrence and behaviour of transient killer whales: seasonal and pod-specific variability, foraging behaviour, and prey handling. Can J Zool 73: 1300-1311

> Baird RW, Dill LM (1996) Ecological and social determinants of group size in transient killer whales. Behav Ecol 7: 408-416

$>$ Baird RW, Whitehead H (2000) Social organization of mammal-eating killer whales: group stability and dispersal patterns. Can J Zool 78:2096-2105

Barrett-Lennard LG, Heise K, Saulitus E, Ellis G, Matkin C (1995) The impact of killer whale predation on Steller sea lion populations in British Columbia and Alaska. Report prepared for the Marine Mammal Research Unit, University of British Columbia, Vancouver, BC

Barrett-Lennard LG, Matkin CO, Durban JW, Saulitis EL, Ellifrit D (2011) Predation on gray whales and prolonged feeding on submerged carcasses by transient killer whales at Unimak Island, Alaska. Mar Ecol Prog Ser 421: 229-241

> Dahlheim ME, White PA (2010) Ecological aspects of transient killer whales Orcinus orca as predators in southeastern Alaska. Wildl Biol 16:308-322

- DeMaster DP, Trites AW, Clapham P, Mizroch S, Wade P, Small RJ, Ver Hoef J (2006) The sequential megafaunal collapse hypothesis: testing with existing data. Prog Oceanogr 68:329-342

Eberhardt LL (2002) A paradigm for population analysis of long-lived vertebrates. Ecology 83:2841-2854

- Eberhardt LL, Siniff DB (1977) Population dynamics and marine mammal management policies. J Fish Res Board Can 34:183-190

> Estes JA, Tinker MT, Williams TM, Doak DF (1998) Killer whale predation on sea otters linking oceanic and nearshore ecosystems. Science 282:473-476

> Ford JKB, Ellis GM, Matkin DR, Balcomb KC, Briggs D, Morton AB (2005) Killer whale attacks on minke whales: prey capture and antipredator tactics. Mar Mamm Sci 21: 603-619

Ford JKB, Ellis GM, Durban JW (2007) Recovery potential assessment for west coast transient killer whales using coastal waters of British Columbia. Dept Fish Oceans Canada, Sci Advis Sec Res Doc 2007/2008. (www. dfo-mpo.gc.ca/csas/Csas/Publications/ResDocs-DocRech/ 2007/2007_088_e.htm)

> Ford JKB, Ellis GM, Olesiuk PF, Balcomb KC (2010) Linking killer whale survival and prey abundance: food limitation in the oceans' apex predator? Biol Lett 6:139-142 
Fowler CW (1981) Density dependence as related to life history strategy. Ecology 62:602-610

Gaillard JM, Festa-Bianchet M, Yoccoz NG (1998) Population dynamics of large herbivores: variable recruitment with constant adult survival. Trends Ecol Evol 13:58-63

Grimm V, Railsback SF (2005) Individual-based modeling and ecology. Princeton University Press, Princeton, NJ

$>$ Grimm V, Berger U, Bastiansen F, Eliassen S and others (2006) A standard protocol for describing individualbased and agent-based models. Ecol Model 198:115-126

Hassell MP (1981) Arthropod predator-prey systems. In: May RM (ed) Theoretical ecology: principles and applications. Sinauer, Sunderland, MA, p 105-131

Heise K, Barrett-Lennard LG, Saulitis E, Matkin C, Bain D (2003) Examining the evidence for killer whale predation on Steller sea lions in British Columbia and Alaska. Aquat Mamm 29:325-334

Hoelzel AR (1991) Killer whale predation on marine mammals at Punta Norte, Argentina; food sharing, provisioning and foraging strategy. Behav Ecol Sociobiol 29:197-204

Kriete B (1995) Bioenergetics in the killer whale, Orcinus orca. PhD dissertation, University of British Columbia, Vancouver

McCauley E, Wilson WG, De Roos AM (1993) Dynamics of age-structured and spatially structured predator-prey interactions: individual-based models and populationlevel formulations. Am Nat 142:412-442

> Mehta AV, Allen JM, Constantine R, Garrigue C and others (2007) Baleen whales are not important as prey for killer whales Orcinus orca in high-latitude regions. Mar Ecol Prog Ser 348:297-307

Metzgar LH, Boyd E (1988) Stability properties in a model of forage-ungulate-predator interactions. Nat Resour Model 3:3-43

Mizroch SA, Rice DW (2006) Have North Pacific killer whales switched prey species in response to depletion of the great whale populations? Mar Ecol Prog Ser 310: 235-246

Moen R, Pastor JK, Cohen Y (1997) A spatially explicit model of moose foraging and energetics. Ecology 78:505-521

- Noren DP (2011) Estimating field metabolic rates and prey requirements of resident killer whales. Mar Mamm Sci 27:60-77

Olesiuk PF, Bigg MA, Ellis GM (1990) Life history and population dynamics of resident killer whales (Orcinus orca) in the coastal waters of British Columbia and Washington

Editorial responsibility: Hans-Heinrich Janssen, Oldendorf/Luhe, Germany
State. Rep Int Whal Comm Spec Issue 12:209-243

Pfister B, DeMaster DP (2006) Changes in marine mammal biomass in the Bering Sea/Aleutian Islands region before and after the period of commercial whaling. In: Estes JA, DeMaster DP, Doak DF, Williams TM, Brownelle RL (eds) Whales, whaling, and ocean ecosystems. University of California Press, Berkeley, CA, p 116-133

Piatt JF, Sydeman WJ, Wiese F (2007) Introduction: a modern role for seabirds as indicators. Mar Ecol Prog Ser 352: 199-204

Rotella JJ, Link WA, Chambert T, Stauffer GE, Garrott RA (2012) Evaluating the demographic buffering hypothesis with vital rates estimated for Weddell seals for 30 years of mark-recapture data. J Anim Ecol 81:162-173

Springer AM, Estes JA, van Vliet GB, Williams TM and others (2003) Sequential megafaunal collapse in the North Pacific Ocean: an ongoing legacy of industrial whaling? Proc Natl Acad Sci USA 100:12223-12228

Trites AW, Deeke VB, Gregr EJ, Ford JKB, Olesiuk PF (2007) Killer whales, whaling and sequential megafaunal collapse in the North Pacific: a comparative analysis of the dynamics of marine mammals in Alaska and British Columbia following commercial whaling. Mar Mamm Sci 23:751-765

> Wade PR, Barrett-Lennard LG, Black NA, Burkanov VN and others (2007) Killer whales and marine mammal trends in the North Pacific-a re-examination of evidence for sequential megafauna collapse and the prey-switching hypothesis. Mar Mamm Sci 23:766-802

Ward EJ, Holmes EE, Balcomb KC (2009) Quantifying the effects of prey abundance on killer whale reproduction. J Appl Ecol 46:632-640

> Williams R, Noren DP (2009) Swimming speed, respiration rate, and estimated cost of transport in adult killer whales. Mar Mamm Sci 25:327-350

Williams TD, Estes JA, Doak DF, Springer AM (2004) Killer appetites: assessing the role of predators in ecological communities. Ecology 85:3373-3384

Williams R, Krkosek M, Ashe E, Branch TA and others (2011) Competing conservation objectives for predators and prey: estimating killer whale prey requirements for Chinook salmon. PLoS ONE 6:e26738

> Winship AJ, Trites AW, Rosen DAS (2002) A bioenergetic model for estimating the food requirements of Steller sea lions Eumetopias jubatus in Alaska, USA. Mar Ecol Prog Ser 229:291-31281

Submitted: September 7, 2011; Accepted: May 25, 2012 Proofs received from author(s): October 2, 2012 